\title{
Fire Performance of Columns made of Normal and High Strength Concrete: a Comparative Analysis
}

\author{
Thomas Gernay ${ }^{1, a^{*}}$ \\ ${ }^{1}$ The National Fund for Scientific Research FNRS, Structural Engineering Department, University \\ of Liege, Allée de la Découverte 9, 4000 Liege, Belgium \\ athomas.gernay@ulg.ac.be
}

Keywords: Fire, Column, High Strength Concrete, Tall Building, Numerical Analysis, SAFIR ${ }^{\circledR}$.

\begin{abstract}
The use of high strength concrete (HSC) in multi-story buildings has become increasingly popular. Selection of HSC over normal strength concrete (NSC) allows for reducing the dimensions of the columns sections. However, this reduction has consequences on the structural performance in case of fire, as smaller cross sections lead to faster temperature increase in the section core. Besides, HSC experiences higher rates of strength loss with temperature and a higher susceptibility to spalling than NSC. The fire performance of a column can thus be affected by selecting HSC over NSC. This research performs a comparison of the fire performance of HSC and NSC columns, based on numerical simulations by finite element method. The thermal and structural analyses of the columns are conducted with the software SAFIR ${ }^{\circledR}$. The variation of concrete strength with temperature for the different concrete classes is adopted from Eurocode. Different configurations are compared, including columns with the same load bearing capacity and columns with the same cross section. The relative loss of load bearing capacity during the fire is found to be more pronounced for HSC columns than for NSC columns. The impact on fire resistance rating is discussed. These results suggest that consideration of fire loading limits the opportunities for use of HSC, especially when the objective is to reduce the dimensions of the columns sections.
\end{abstract}

\section{Introduction}

High strength concrete (HSC) finds many applications in civil engineering, in particular in tall buildings where it allows to reduce the total amount of material placed and the weight on the foundations. As it carries loads more efficiently than normal strength concrete (NSC), it is also specified where architectural considerations call for small support elements. The reduction in member size that can be obtained with HSC results in an increase in usable area. Alternatively, for a fixed column size, longer spans can be supported which leads to a reduced number of supports. These advantages have resulted in increased use of HSC in high-rise buildings within the last decades.

An important requirement for building structures is the performance under fire situations. Previous research has shown that HSC exhibits distinct behavioral differences with NSC at elevated temperature [1]. The most important differences regard the relative loss of compressive strength with temperature and the occurrence of spalling. For these two aspects, HSC performs worse than NSC, i.e. it experiences higher rates of strength loss with temperature and a higher susceptibility to spalling. In addition, HSC is often used to reduce the size of structural members. However, this reduction may be detrimental to the fire performance as it leads to faster temperature increase in the section core of the members. Reduced section sizes also lead to increased member slenderness, which may lead to increased second-order effects. Bamonte [2] has shown that second-order effects can play a considerable role in stability of HSC columns in fire. For all these reasons, consideration of fire loading may partly neutralize the advantages of HSC. 
The objective of this research is to investigate to what extent the fire performance of structural members is affected when HSC is used instead of NSC. The study focuses on columns. It is assumed that HSC is selected to replace NSC, whether to reduce the section size for a given load to carry, or to increase the spans and hence the load for a given section size. The consequences of these two design choices on the fire behavior is investigated. In the paper, numerical analyses of reinforced concrete columns made of HSC and NSC are performed to establish the time to failure under standard ISO fire as a function of the applied load ratio on the columns.

\section{Method}

The thermal analyses of the sections and the structural analyses of the columns are conducted with the nonlinear finite element software SAFIR ${ }^{\circledR}$ [3]. This software has been developed at University of Liege for the analysis of building structures in fire.

The reduction of compressive strength at elevated temperature is considered according to the values given in Eurocode 1992-1-2 [4]. For HSC, strength properties are given in three classes in Eurocode, which depend on the characteristic strength of concrete at ambient temperature. The higher the class, the more pronounced the relative reduction in strength is with temperature, see Fig. 1. This effect is particularly visible for the lower temperature range $\left(50^{\circ} \mathrm{C}-250^{\circ} \mathrm{C}\right)$ and it remains true for Class 3 up to $800^{\circ} \mathrm{C}$. The HSC laws of Fig. 1 have been implemented in the software SAFIR ${ }^{\circledR}$. For NSC, siliceous aggregates are assumed. Note that the reduction in strength is more pronounced for NSC with siliceous aggregates than calcareous aggregates; yet even with siliceous aggregates, NSC remains comparatively less affected by temperature than HSC.

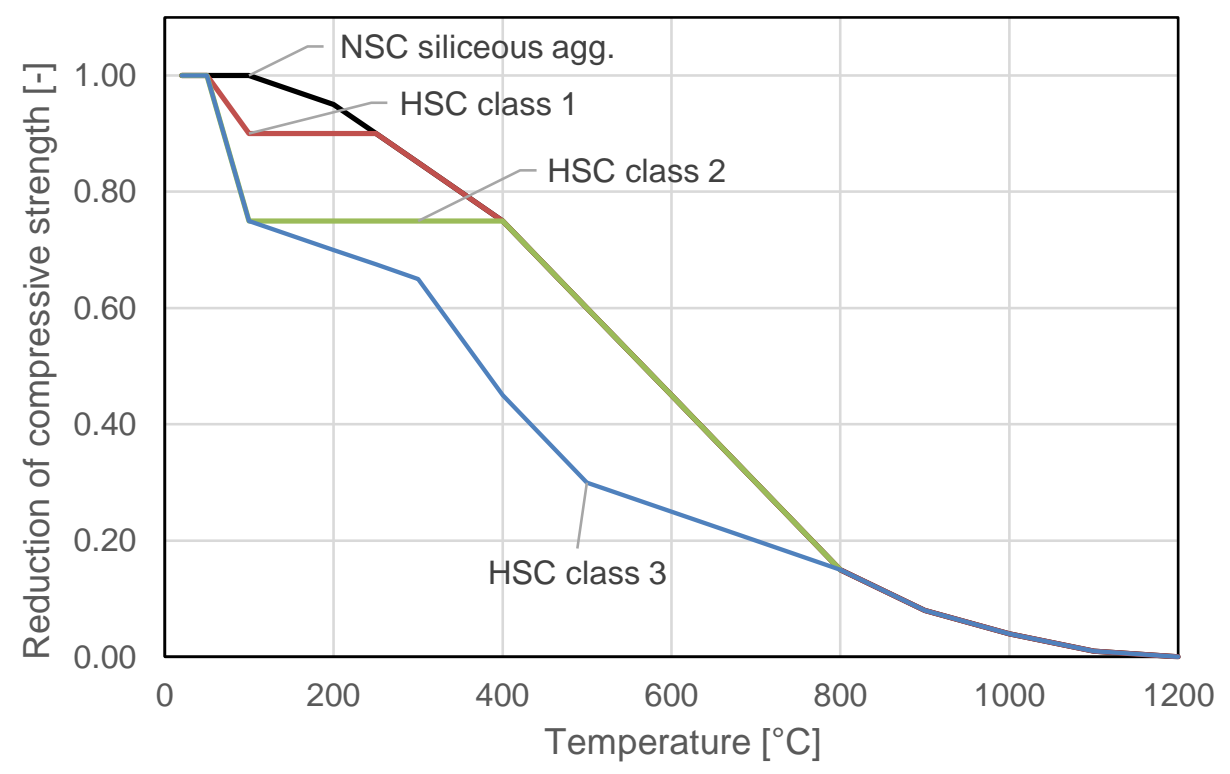

Fig. 1 Reduction of concrete compressive strength at elevated temperature (from [4]) Class 1: C55/67, C60/75 - Class 2: C70/85, C80/95 - Class 3: C90/105

Currently the modeling of the hygro-thermo-mechanical mechanisms leading to spalling in fireexposed concrete remains a very challenging task. No satisfying model has emerged for use at the scale of a building structural member. In thermo-mechanical finite element software such as SAFIR $^{\circledR}$, spalling cannot be predicted because the moisture flow and the development of pore pressures during heating are not captured. Meanwhile, extensive research efforts have been conducted on the measures to employ to prevent the apparition of spalling [5]. The Eurocode [4] gives different methods that should be provided in particular for high strength concrete. Hence, the designer is required to take the appropriate measures when using HSC, e.g. by including in the 
concrete mix at least $2 \mathrm{~kg} / \mathrm{m}^{3}$ of monofilament polypropylene fibers. Such measures allow mitigating the phenomenon of spalling. Assuming this type of measure is adopted in the design in accordance with the codes, and given the complexity of predicting spalling occurrence in numerical simulations, spalling is neglected in this study.

Four concrete characteristic (cylinder) strengths are taken into account in the analyses: $40 \mathrm{MPa}$ (NSC), $60 \mathrm{MPa}$ (HSC class 1), $70 \mathrm{MPa}$ (HSC class 2) and $90 \mathrm{MPa}$ (HSC class 3).

The studied columns are $2.5 \mathrm{~m}$ high and simply supported at their extremities (Fig. 2). A geometrical imperfection of sinusoidal shape with maximum amplitude equal to $5 \mathrm{~mm}$ (height/500) is considered. The columns have a square cross section and are reinforced with 8 steel bars of $20 \mathrm{~mm}$ diameter. The concrete cover to the axis of the rebars is $35 \mathrm{~mm}$. The material models given in Eurocode [4] are adopted for steel and concrete at elevated temperature. Yet in the concrete model, the transient creep strain is considered explicitly as this has proven to provide more accurate results [6-8].

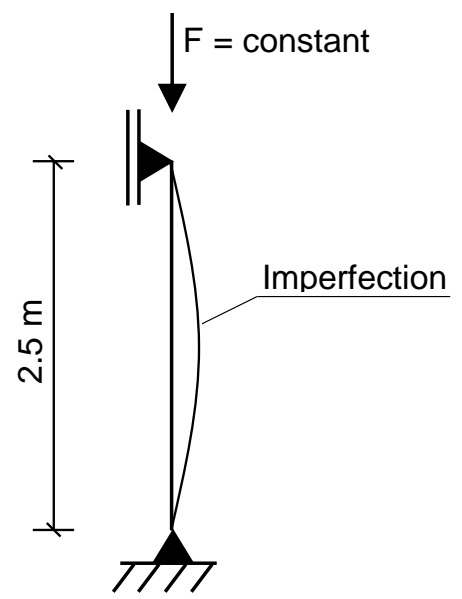

Fig. 2 Concrete column considered for the comparative analysis

The columns are subjected to a vertical load at the top and then to ISO fire on their four sides. The applied load is kept constant during the fire. For a given load, a transient thermo-mechanical simulation is performed until failure of the column, or up to maximum four hours of fire exposure if the column does not fail within four hours. The simulation is repeated for different load ratios. In the end, the relationship between the applied load ratio and the fire resistance time is obtained for each column.

The comparative analysis between HSC and NSC considers two different configurations, namely: columns with the same load bearing capacity (hence a smaller cross section for the HSC column), and columns with the same cross section.

Columns with the same load bearing capacity. In this first configuration, columns with approximately the same load bearing capacity are compared. Here, the benefit of using HSC over NSC lies in the fact that, to support a given load, the cross section dimensions of the columns can be reduced.

For each concrete strength, the dimension $\mathrm{c}$ of the square cross section is determined as the minimum dimension for which the column load bearing capacity reaches at least $14,500 \mathrm{kN}$, see Table 1. In addition, c must be a multiple of $5 \mathrm{~cm}$, for constructional reason. According to these design criteria, the dimension c of the square section is smaller when a higher concrete class is used. The (unfactored) load bearing capacity of the columns at ambient temperature is determined by numerical simulation with SAFIR ${ }^{\circledR}$. The second-order effects are taken into account.

As can be seen in Table 1, the bearing capacity of the column $\left(\mathrm{N}_{\mathrm{R}, \mathrm{SAFIR}}\right)$ at ambient temperature is smaller than the full sectional capacity in compression $\left(\mathrm{N}_{\mathrm{ck}}+\mathrm{N}_{\mathrm{sk}}\right)$. The initial imperfection 
influences the failure of the columns by buckling. Second-order effects are more pronounced for smaller cross-section sizes (HSC 3) than for larger sizes (NSC). Also, they are expected to be more pronounced at elevated temperature than at ambient temperature, because of the stiffness reduction caused by the fire.

The section factor $\mathrm{A} / \mathrm{V}$ increases with the concrete strength, as a result of the decrease in the section size. Hence, the columns made of HSC will be heated faster than the column made of NSC.

Table 1. Characteristics of the columns made of NSC and HSC, with fixed load bearing capacity

\begin{tabular}{cccccccccc}
\hline $\begin{array}{c}\text { Concrete } \\
{[-]}\end{array}$ & $\begin{array}{c}\mathrm{f}_{\mathrm{ck}} \\
{[\mathrm{MPa}]}\end{array}$ & $\begin{array}{c}\mathrm{c} \\
{[\mathrm{cm}]}\end{array}$ & $\begin{array}{c}\mathrm{A}_{\mathrm{s}} \\
{\left[\mathrm{cm}^{2}\right]}\end{array}$ & $\begin{array}{c}\mathrm{A}_{\mathrm{c}} \\
{\left[\mathrm{cm}^{2}\right]}\end{array}$ & $\begin{array}{c}\mathrm{N}_{\mathrm{ck}} \\
{[\mathrm{kN}]}\end{array}$ & $\begin{array}{c}\mathrm{f}_{\mathrm{sk}} \\
{[\mathrm{MPa}]}\end{array}$ & $\begin{array}{c}\mathrm{N}_{\mathrm{sk}} \\
{[\mathrm{kN}]}\end{array}$ & $\begin{array}{c}\mathrm{N}_{\mathrm{R}, S A F I R} \\
{[\mathrm{kN}]}\end{array}$ & $\begin{array}{c}\mathrm{A} / \mathrm{V} \\
{\left[\mathrm{m}^{-1}\right]}\end{array}$ \\
\hline NSC & 40 & 60 & 25.1 & 3574.9 & 14299 & 500 & 1257 & 15130 & 6.7 \\
HSC 1 & 60 & 50 & 25.1 & 2474.9 & 14849 & 500 & 1257 & 15527 & 8.0 \\
HSC 2 & 70 & 45 & 25.1 & 1999.9 & 13999 & 500 & 1257 & 14617 & 8.9 \\
HSC 3 & 90 & 40 & 25.1 & 1574.9 & 14174 & 500 & 1257 & 14654 & 10.0 \\
\hline
\end{tabular}

Columns with the same cross section. In this second configuration, columns with the same cross section dimensions are analyzed. In such a case, the use of HSC allows for the column to carry a larger load than if NSC was used. Therefore, it is possible, for instance, to increase the spans and reduce the number of columns by using HSC instead of NSC.

The columns have a square cross section of $50 \mathrm{~cm}$ side. The load bearing capacity at ambient temperature, obtained by numerical simulation, increases with the concrete strength (Table 2). In this configuration, the section factor and hence the temperature evolution is identical in the HSC and the NSC sections.

Table 2. Characteristics of the columns made of NSC and HSC, with fixed section size

\begin{tabular}{cccccccccc}
\hline $\begin{array}{c}\text { Concrete } \\
{[-]}\end{array}$ & $\begin{array}{c}\mathrm{f}_{\mathrm{ck}} \\
{[\mathrm{MPa}]}\end{array}$ & $\begin{array}{c}\mathrm{c} \\
{[\mathrm{cm}]}\end{array}$ & $\begin{array}{c}\mathrm{A}_{\mathrm{s}} \\
{\left[\mathrm{cm}^{2}\right]}\end{array}$ & $\begin{array}{c}\mathrm{A}_{\mathrm{c}} \\
{\left[\mathrm{cm}^{2}\right]}\end{array}$ & $\begin{array}{c}\mathrm{N}_{\mathrm{ck}} \\
{[\mathrm{kN}]}\end{array}$ & $\begin{array}{c}\mathrm{f}_{\text {sk }} \\
{[\mathrm{MPa}]}\end{array}$ & $\begin{array}{c}\mathrm{N}_{\text {sk }} \\
{[\mathrm{kN}]}\end{array}$ & $\begin{array}{c}\mathrm{N}_{\mathrm{R}, \mathrm{SAFIR}} \\
{[\mathrm{kN}]}\end{array}$ & $\begin{array}{c}\mathrm{A} / \mathrm{V} \\
{\left[\mathrm{m}^{-1}\right]}\end{array}$ \\
\hline NSC & 40 & 50 & 25.1 & 2474.9 & 9899 & 500 & 1257 & 10764 & 8.0 \\
HSC 1 & 60 & 50 & 25.1 & 2474.9 & 14849 & 500 & 1257 & 15527 & 8.0 \\
HSC 2 & 70 & 50 & 25.1 & 2474.9 & 17324 & 500 & 1257 & 17907 & 8.0 \\
HSC 3 & 90 & 50 & 25.1 & 2474.9 & 22274 & 500 & 1257 & 22670 & 8.0 \\
\hline
\end{tabular}

\section{Numerical Analyses of the Columns}

First, thermal analyses of the sections are conducted under ISO fire exposure. The concrete has a density of $2400 \mathrm{~kg} / \mathrm{m}^{3}$ with $2 \%$ moisture content in weight. The emissivity is taken as 0.7 and the coefficient of convection between concrete and the air is $25 \mathrm{~W} / \mathrm{m}^{2} \mathrm{~K}$.

Fig. 3 shows the temperature distribution after 2 hours of fire exposure in the $60 \mathrm{~cm} \times 60 \mathrm{~cm}$ section (NSC) and in the $40 \mathrm{~cm} \mathrm{x} 40 \mathrm{~cm}$ section (HSC 3). Due to its lower section factor, the NSC section takes much longer to heat. After 2 hours of fire, a large part at its core is still below $100^{\circ} \mathrm{C}$. This provides the stocky NSC section a larger inherent fire resistance compared with the more slender HSC section.

Then, structural analyses are conducted for the heated columns. Three-noded, two-dimensional beam finite elements are used. The time-temperature evolution in the sections is taken from the thermal analyses previously conducted. The structural analyses take into account geometrical and material nonlinearity, including large deflections. It also accounts for thermal expansion. The simulations are run up to four hours of ISO fire exposure, and the time to failure is recorded as a function of the applied load ratio. 


\section{Results}

Fig. 4 shows the relationship between the applied load ratio and the time to failure under ISO fire, for the columns of Table 1 with (approximately) the same load bearing capacity. It can be seen that the fire performance degrades with the increase in concrete class.
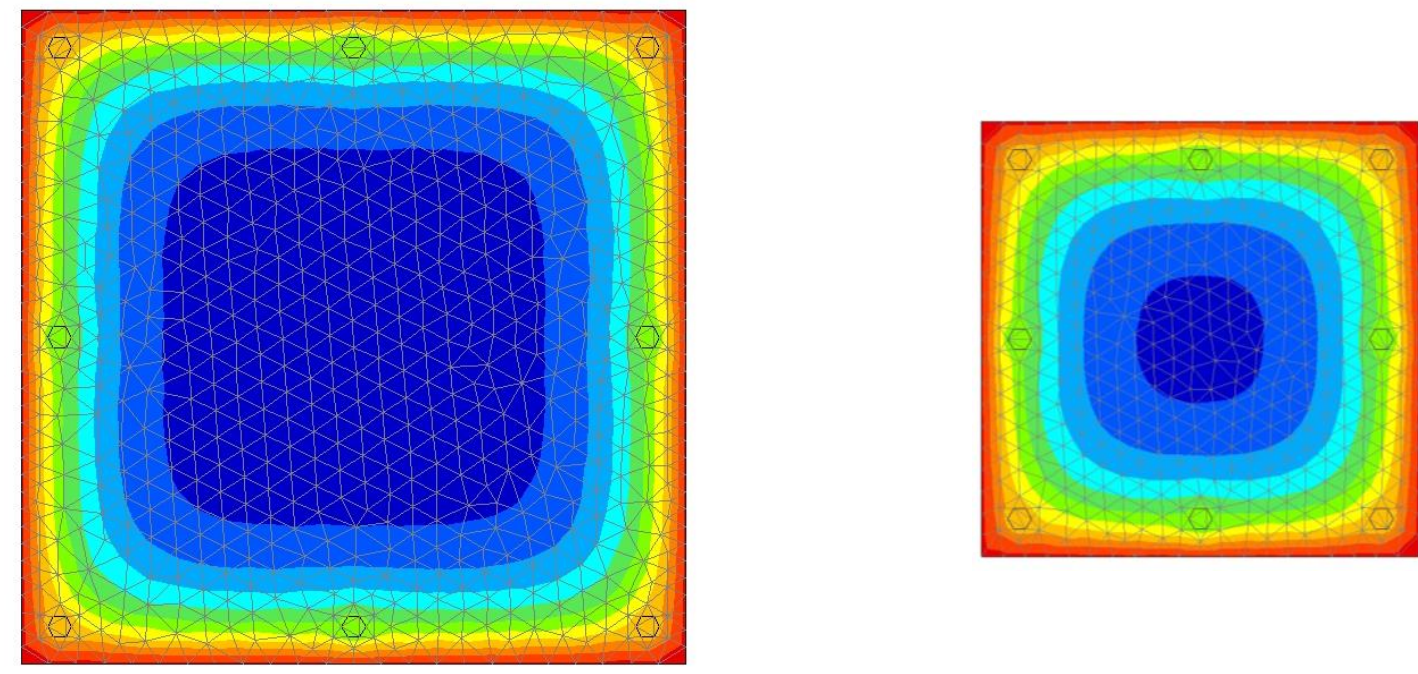

Fig. 3 Temperature distribution in the sections $60 \times 60\left(\mathrm{~cm}^{2}\right)$ and $40 \times 40\left(\mathrm{~cm}^{2}\right)$ after 2 hours of fire

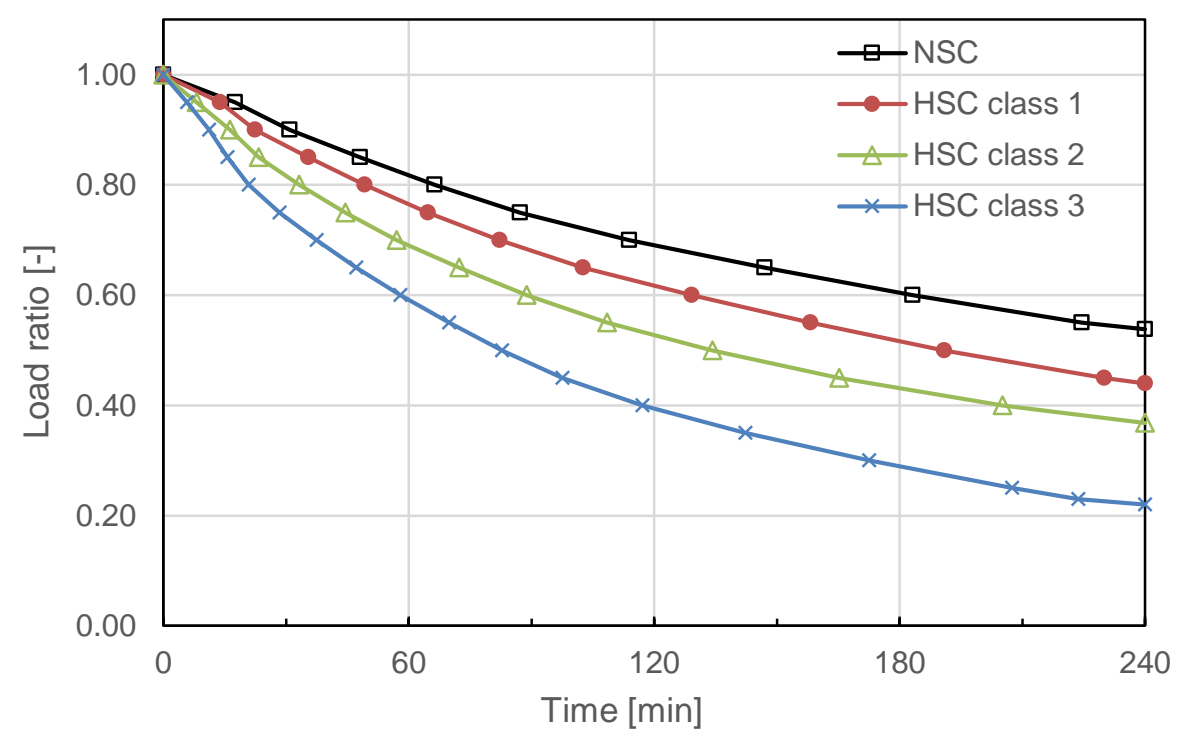

Fig. 4 Relationship between applied load ratio on the column and fire resistance time. The columns are designed for a given load bearing capacity (the section size varies with the strength).

For instance, let consider that a 120 minutes fire resistance is required for the building members. To achieve the desired fire resistance time, the load ratio on the NSC column (in the fire situation) must be limited to $69 \%$ of the maximum load capacity at ambient temperature. In comparison, this load ratio must be limited to $39 \%$ for the column in HSC class 3. Before the fire, the NSC and HSC class 3 columns could carry the same load; however after 120 minutes of ISO fire exposure, the NSC column can carry $10,400 \mathrm{kN}$ whereas the HSC class 3 column can only carry $5715 \mathrm{kN}$. 
Note that, in accidental design situations such as fire, the combination of actions, the safety factors on the demand (D) and on the capacity (C) are different than for persistent design situations, due to the small probability of occurrence of the former. As a result, a structural member designed to its full design capacity $(\mathrm{D} / \mathrm{C}=100 \%)$ in conditions of normal use is only subjected to a fraction of its "real" capacity (typically, between $40 \%$ and $70 \%$ ) in the fire design situation. This comes from a decrease in D (because variable actions are not likely to exist at their full value simultaneously to a fire) and an increase in $\mathrm{C}$ (because the partial factors for materials for ultimate limit states are less detrimental for accidental than for persistent design situations).

Therefore, considering the typical values of D/C for fire design situation, the NSC column is very likely to achieve the R120 fire rating. In contrast, the R120 fire rating criterion raises an issue for the HSC class 3 column. The cross section dimensions of the HSC column would probably need to be increased to satisfy to the fire criterion. Thus in this case, consideration of the fire loading limits the benefits of the use of HSC instead of NSC.

Fig. 5 plots the evolution of the horizontal displacement at mid-height for the NSC and the HSC class 3 columns of Table 1 loaded at $60 \%$ load ratio and subject to fire. It can be seen that the columns fail with a sudden increase in transversal displacement after respectively 183 minutes and 58 minutes of ISO fire exposure.

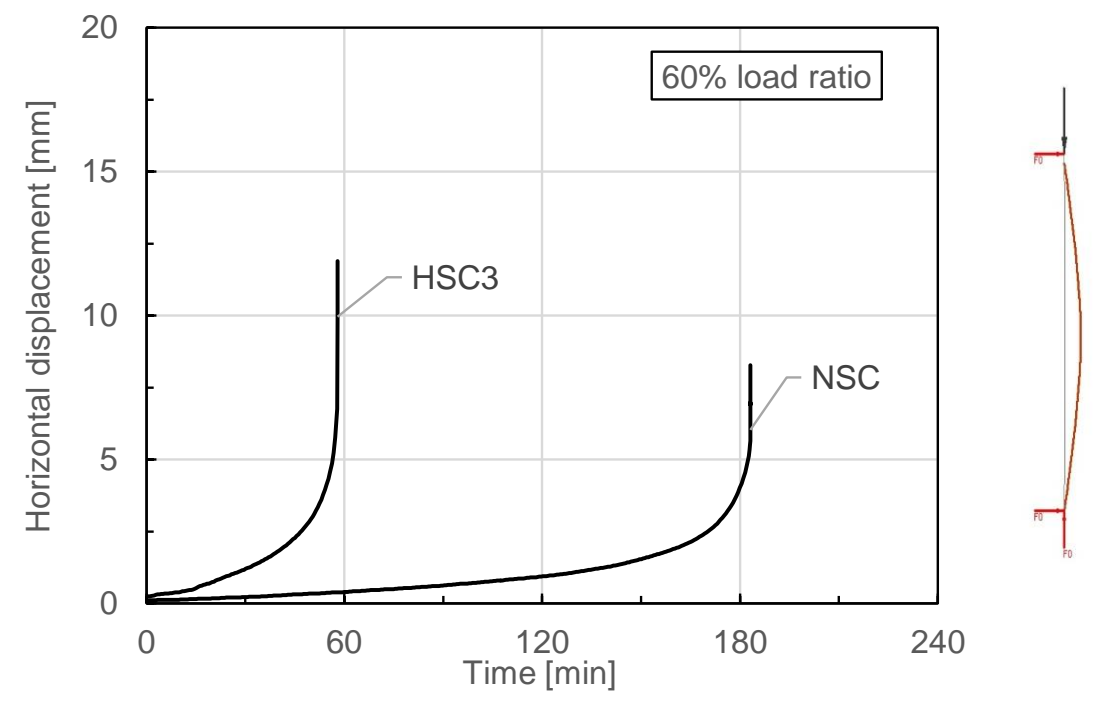

Fig. 5 Evolution of horizontal displacement at mid-height for NSC and HSC class 3 columns loaded at $60 \%$ of their capacity at ambient temperature and subject to ISO fire exposure.

The differences in fire behavior between the columns of different concrete strengths, observed in Fig. 4, are caused by different factors. First, the relative reduction of strength with temperature depends on the concrete characteristic strength (Fig. 1). The reduction is more severe for a HSC class 3 than for a class 2 , and for a class 2 versus a class 1 . The other factors are related to the fact that, in this analysis, the cross section size decreases with the concrete characteristic strength. Therefore, the section factor increases for higher concrete strengths and the heat transfer towards the section core is much faster, e.g. when comparing the section in HSC class 3 with the section in NSC (Fig. 3). Another effect of the reduction in cross section size is an increase in slenderness, which may also play a detrimental role for small cross sections in HSC.

In order to eliminate the effects of different cross section sizes, columns with the same dimensions are compared in the second set of analysis. In this case, the load bearing capacity of the columns vary with the concrete strength (Table 2). As the analysis is conducted in terms of load ratios, the fire performance of these columns can still be compared. Fig. 6 shows the relationship 
between the applied load ratio and the time to failure under ISO fire, for the columns which all have a cross section of $50 \mathrm{~cm}$ side.

As shown in Fig. 6, there remains a difference in fire performance between concretes of different characteristic strengths. The column in HSC class 3 exhibits a more severe reduction in load capacity under fire compared with the columns in NSC and in HSC class 1. The column in HSC class 2 exhibits an intermediate behavior. The results for NSC and HSC class 1 are almost identical. Overall, the difference between the curves is less pronounced than in the first set of analysis. This was expected, since the factors related to the variation of section size have been eliminated in this second configuration. Here, the different behaviors are only due to the differences in material properties at elevated temperature (Fig. 1).

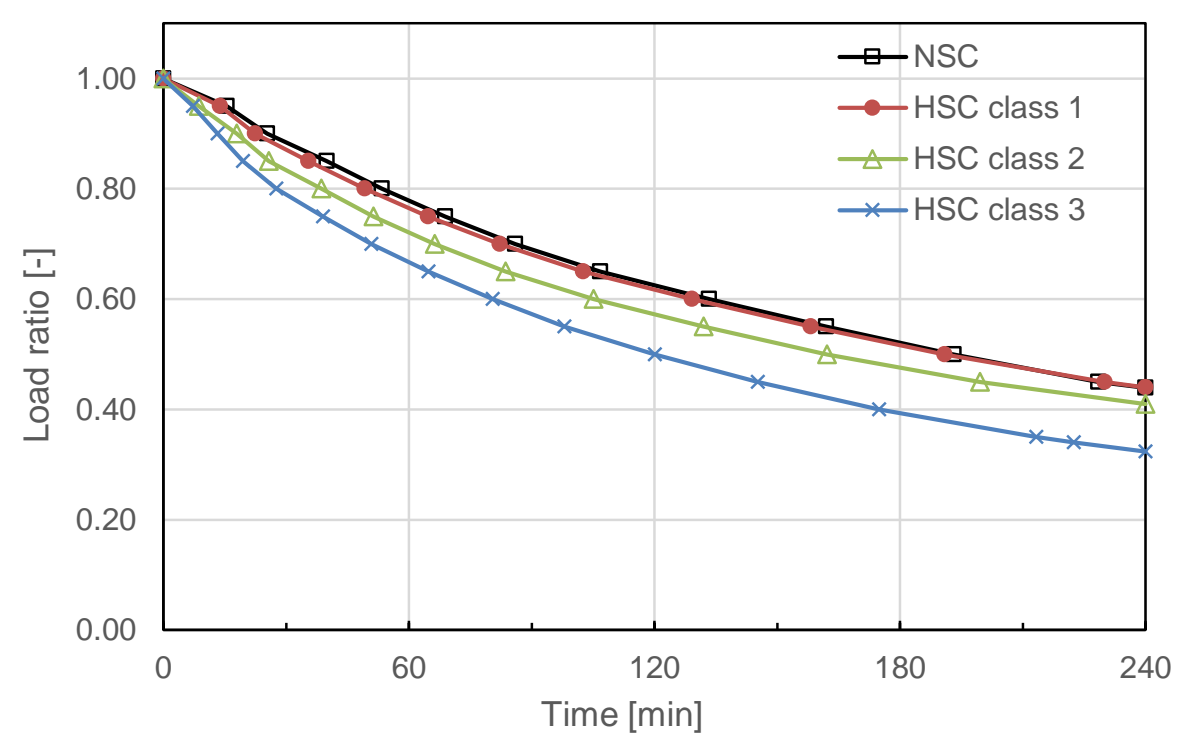

Fig. 6 Relationship between applied load ratio on the column and fire resistance time. The columns have the same cross section (the load bearing capacity varies with the strength).

Assuming a target fire resistance rating at 120 minutes for these columns, the maximum load ratio (in fire design situation) can be derived from Fig. 6. It equals $62 \%$ for the NSC column, $61 \%$ for the HSC 1 column, 57\% for the HSC 2 column and 50\% for the HSC 3 column. Inversely, assuming that the columns have to carry $60 \%$ of their maximum load bearing capacity during the fire, the corresponding fire resistance time can be obtained. It ranges between 133 min for the NSC column and $80 \mathrm{~min}$ for the HSC 3 column. These results show that, even when the same sections are used, the fire performance of members in HSC is inherently worse than for members in NSC, due to a more severe degradation of the mechanical properties at elevated temperature.

\section{Conclusion}

This study has investigated the comparative fire performance of columns made of normal strength concrete and high strength concrete. HSC is increasingly used in (high-rise) building structures and therefore the fire behavior of HSC members needs to be properly comprehended. Typically, HSC is preferred over NSC because it allows for a reduction in the section size of the members, or in the number of supports.

At the material level, HSC experiences a reduction of material properties with temperature that is more severe than for NSC. This results in a load bearing capacity that decreases faster for HSC columns than for NSC columns during the fire. While the studied column in C40/50 retains $62 \%$ of its initial capacity after 120 minutes of standard fire exposure, the same column in C90/105 only retains $50 \%$ of its. 
The comparative performance of HSC columns under fire is particularly affected when HSC is used to reduce the dimensions of the column cross section. Smaller cross sections lead to faster temperature increase in the core and increased slenderness. These effects add to the differences in mechanical properties, all of which contribute to make the HSC columns more vulnerable to fire than NSC columns.

The analyses have been performed under the assumption that spalling is prevented. This can be the case provided that, for instance, the proper amount of polypropylene fibers is added in the mix. However, if the occurrence of spalling is not prevented, this phenomenon will also affect negatively the performance of HSC members.

Therefore, it appears that the fire loading situation has to be taken into account carefully when it is decided to use HSC instead of NSC in a building project. The fire design situation may limit the opportunities for use of HSC, in particular when the objective is to reduce the dimensions of the columns sections. In the future, additional studies should be conducted to explore the optimum relationships for columns between, on the one hand, the load bearing capacity and fire resistance time to achieve, and on the other hand, the concrete characteristic strength and section size to use.

\section{References}

[1] L. Phan, N. Carino, Review of Mechanical Properties of HSC at Elevated Temperature, J. Mater. Civ. Eng. (ASCE) 10:1(58) (1998) 58-65.

[2] P. Bamonte, On the role of second-order effects in HSC columns exposed to fire, in: Proc. 5th Int. Conf. Structures in Fire - SiF’08, Singapore, May 28-30 (2008) 440-450.

[3] J.M. Franssen, SAFIR: a thermal/structural program for modeling structures under fire. Eng. J. Am. Inst. Steel. Constr. 42(3) (2005) 143-158.

[4] EN 1992-1-2. Eurocode 2 - design of concrete structures - Part 1-2: general rules - structural fire design, CEN, Brussels, 2004.

[5] P. Pliya, A-L. Beaucour, A. Noumowé, Contribution of cocktail of polypropylene and steel fibres in improving the behaviour of high strength concrete subjected to high temperature, Construction and Building Materials 25 (2011) 1926-1934.

[6] T. Gernay, J.M. Franssen, A formulation of the Eurocode 2 concrete model at elevated temperature that includes an explicit term for transient creep, Fire Saf. J. 51 (2012) 1-9.

[7] T. Gernay, Effect of Transient Creep Strain Model on the Behavior of Concrete Columns Subjected to Heating and Cooling, Fire Technology 48(2) (2012) 313-329.

[8] T. Gernay, A multiaxial constitutive model for concrete in the fire situation including transient creep and cooling down phases (Ph.D. thesis), University of Liege, 2012. 